RAPHISA.

Revista de Antropología y Filosofía de lo Sagrado Review of Anthropology and Philosophy of the Sacrum

ISSN: 2530-1233 No 8, diciembre (2020) pp.: 135-155

Recibido:24/11/2020 Aceptado:30/11/2020

\title{
FORO ISLÁMICO GLOBAL: PANISLAMISMO DI- GITAL EN TIEMPOS DE COVID-19
}

\section{GLOBAL ISLAMIC FORUM: DIGITAL PAN-ISLAMISM IN THE TIME OF COVID-19}

\section{Sylvie Taussig//Yolotl Valadez ${ }^{2}$ Centre National de la Recherche Scientifique (Francia)}

\begin{abstract}
Resumen: La epidemia del coronavirus ha afectado profundamente las prácticas religiosas en casi todo el mundo pues las políticas de aislamiento obstaculizan el ejercicio comunitario de la vivencia espiritual propia de muchos cultos. Sin embargo para algunos sectores la pandemia ha posibilitado la generación de nuevas prácticas y formas de crear comunidad a la distancia utilizando para ello la web. Este documento es una reflexión general sobre las religiones mundializadas y el COVID-19, que busca aportar un elemento de análisis para entender el islam latino y cómo se organiza frente a la crisis, pues veremos que a pesar de la pandemia el trabajo de proselitismo no sólo no se ha detenido, sino que se ha ampliado, a la par que se propone la creación de una ummah global. Y finalmente se da una idea general de la recomposición de una parte del islam latino y de ciertos grupos del islam mundializado.
\end{abstract}

\section{Palabras clave: ISLAM-GLOBALIZACIÓN-COVID-19-ISLAM LATINO}

\begin{abstract}
The coronavirus epidemic has profoundly affected religious practices in almost all parts of the world, as policies of isolation hinder the communitarian exercise of the spiritual experience characteristic of many cults. However, for some sectors the pandemic has made it possible to generate new practices and ways of creating community from a distance
\end{abstract}

[1] (sylvie.taussig@cnrs.fr) Investigadora del Centro Nacional de Investigación Científica (CNRS -UMR8230), especializada en Ciencias Politicas. Enfoca su trabajo en la Historia de las ideas en el siglo XVII, teorías de la secularización, religión y política e islam globalizado, que lleva a cabo en el Perú y en América Latina, entre sus publicaciones podemos encontrar, "De l'islam politique à la théologie musulmane de la libération", "Le mythe de l'islam précolombien", "Néo-chamanisme et néo-colonialisme : entre chaos et déstructuration sociale".

[2] (yolino3@comunidad.unam.mx) Historiadora por la UNAM y profesora de Historia de Medio Oriente en la misma universidad, sus líneas de investigación son las relaciones entre Medio Oriente y América Latina así como la mundialización del islam en contextos latinoamericanos. Entre sus publicaciones se encuentra "Halal et halalisation au Mexique" y "Le mariage islamique en Amerique latine developpement et enjeux" elaborados junto con Sylvie Taussig. 
using the web. This document is a general reflection on globalized religions and the COVID-19, which seeks to provide an element of analysis for understanding Latin Islam and how it is organized in the face of the crisis, since we will see that despite the pandemic, the work of proselytism has not only not stopped, but has expanded, while proposing the creation of a global umma (community). And finally, there is a general idea of their composition of a part of Latin Islam and of certain groups of globalized Islam.

\section{Key words: ISLAM-GLOBALIZATION-COVID-19-LATIN ISLAM}

El 18 y 19 de abril de 2020 se llevó a cabo a través de la red social Facebook, una conferencia virtual de musulmanes "hispanos" con el título "Entregándose al islam: cómo construir una base espiritual sólida"3. Este foro en línea tenía un triple objetivo, por una parte, organizar un evento mundial, a pesar del encierro, o gracias a él; por otra, tratar de construir una comunidad de creyentes virtuales, que no necesiten estar presentes físicamente, y, finalmente, aportar algunas directrices para preparar el Ramadán. El análisis de este evento, así como de los participantes, su organización y discursos nos darán una idea de la reorganización de una parte del islam en el mundo hispanohablante y su uso y proyección de los medios digitales para continuar el trabajo de dawah a pesar de la pandemia.

Es importante señalar aquí que el tema de las practicas religiosas a través de la red se ha venido estudiado ya desde las últimas décadas, pues es precisamente cuando han empezado ha proliferar. Aunque la mayoría de estos estudios se ha centrado en el universo cristiano existen trabajos muy interesantes sobre el islam, por ejemplo el de Gary Bunt, iMuslims: rewiring. The house of Islam $^{4}$ donde analizó una gran cantidad de sitios web islámicos proponiendo la idea de un entorno ciber-islámico donde se pueden encontrar todo tipo de páginas, mostrando que no existe una ummah online sino muchas, sin embargo este es un entorno que cambia fácilmente, los problemas que hace unos años eran centrales en las predicas de algunas corrientes (visibles en sus sitios web) ahora se han modificado, respondiendo a un avance del islam, un avance cibernético pero también físico y económico (por ejemplo, el mercado halal). La carencia de una institución que regule prácticas y cánones, así como de quien certifique la

[3] Aquí el primer video https://www.facebook.com/WhyIslam/videos/544428663151140/; el segundo videohttps://www.facebook.com/ForoIslamicoGlobal/videos/229731291566979/

[4] BUNT, Gary R., iMuslims: Rewiring the house of Islam, Chapel Hill 2009. Véase también CAMPBELL, Heidi, Digital religion: Understanding Religious Practice in New Media Worlds, London/New York 2013; ACHOURI, Fatima, Islam 2.0. Entre émancipation et aliénation, Paris 2018. 
autoridad de los dirigentes es uno de los grandes problemas al estudiar este fenómeno, más cuando, como en este caso hablamos de una religión mundializada. Las religiones han sido transnacionales durante mucho tiempo, no solo por las migraciones, sino también por el reclamo de universalidad de las grandes religiones desprendidas de su territorio. La noción de religión globalizada se refiere a la idea de que las religiones, que tienen seguidores en todo el mundo, con diferentes culturas y menos experiencia histórica que permita acumular una teología, libros, prácticas centenarias, constituyen, para mantener la unidad en la diversidad y no perderse en la desterritorialización y reterritorialización, no necesariamente de forma consciente, una versión simplificada de sus dogmas y prácticas. Vemos esto particularmente en el caso del islam en el continente americano, donde es la rama sunita la que domina el panorama religioso islámico. El islam se presenta así como el monoteísmo por excelencia, donde sólo importa la relación de los fieles con Dios y las reglas de la vida (llamada «forma de vida»), una religión que es a la vez muy simple y holística. ${ }^{5}$ Los estudios sobe el islam en Estados Unidos han propuesto la categoría de un islam latino, es decir el practicado y difundido por la comunidad que se adscribe como latina. El concepto de latino en Estados Unidos surgió en la década de 1980, entre la comunidad migrante proveniente de América Latina, respondiendo en parte a la categorización gubernamental que los clasificaba como hispanos, los movimientos chicanos y puertorriqueños, propusieron el término latino para auto adscribirse, siendo este termino el que abarcaba un conjuntos de prácticas, tradiciones y costumbres que los identificaban. ${ }^{6}$ Dentro de la heterogeneidad de esta comunidad latina podemos encontrar que hay una parte numerosa de conversos al islam, que en los últimos años han adquirido mayor relevancia, no sólo por el número de sus miembros sino por su gran activismo militante. Hasta hace unos años el término latino fue muy importante dentro de este grupo, pues se hablaba de un islam aculturizado, que tomaba los símbolos y prácticas de su cultura y los asimilaba dentro de su práctica religiosa, no era extraño ver en sus reuniones o charlas símbolos de latinidad como el sombrero mexicano o vestimentas tradicionales, sin embargo, como veremos más adelante esto comienza a cambiar debido precisamente a la mundialización del islam.

En este contexto la web ha sido fundamental para trasmitir este corpus de enseñanzas simplificadas no sólo creando sitios web de difusión ${ }^{7}$,

[5] MANDAVILLE, Peter, Transnational Muslim Politics: Reimagining the Umma, London 2001 (revised paperback edition, 2003).

[6] OBOLER Suzzane, "La identidad latina de ayer y de hoy" en Elaine Levine Leiter, La migración y los latinos en Estados Unidos: visiones y conexiones, México 2008, p. 427.

[7] DAWSON, Lorne L. y Doouglas. E. COWAN, Religion online: Finding faith on the 
sino que en el contexto de la pandemia y el confinamiento impuesto en la mayoría de países, han utilizado las plataformas ya existentes (páginas web, Facebook, Twitter) e incluido nuevas como zoom y similares, para organizar conferencias, congresos, talleres, foros, y seguir no únicamente haciendo dawah, sino intentando construir una comunidad de creyentes cibernética, como es el caso del foro que aquí analizamos.

Este evento, anunciado semanas antes en diversas páginas de musulmanes latinos, fue organizado por el $\mathrm{ICNA}^{8}$ a través de su proyecto de divulgación WhyIslam?/ Porqué islam? ${ }^{9}$ con la colaboración de IslamInS-

internet. London/New York 2004.

[8] En 1968 surgió el IslamicCircle of North America (ICNA), una organización conformada mayoritariamente por asiáticos partidarios políticos del movimiento Jamaat-i Islami, enfocada a ayudar a los musulmanes en Estados Unidos pero principalmente orientada a impartir educación. Desde 1980 se ha enfocado en la creación de diversos proyectos para atender a la variada comunidad musulmana de Estados Unidos a través de convenciones anuales, cursos certificados sobre islam y sucursales a lo largo y ancho del país. Pero también ha enfocado sus esfuerzos en los no musulmanes con programas de Dawah para convertirlos al islam; ejemplo de ello ha sido uno de sus programas con mayor eco, WhyIslam? Este programa, además de ser un movimiento proselitista, atiende a los sectores étnicos islámicos de Estados Unidos en su idioma, como la creciente comunidad musulmana latina. Llevado también su proselitismo a nivel internacional reuniendo a musulmanes fuera de Estados Unidos. El ICNA al igual que otras instituciones islámicas ha incurrido en el campo político y en movimientos por la defensa de los derechos civiles de los musulmanes en Estados Unidos. Se declara, al igual que los diferentes grupos e instituciones islámicas, en contra del terrorismo. No obstante, a su posición antiterrorista, en 2005 ICNA fue investigado por posibles nexos con al-Qaeda. Quizás se debió a que el movimiento Jammaat-i Islami influyó en SayyidQutb, la Hermandad Musulmana y en Al Qaeda, pero en su versión estadounidense no se encontró evidencia. MEDINA, Arely, Identidades en los mexicanos musulmanes en Estados Unidos: la comunidad islámico latina transnacional, Guadalajara 2019, p. 78.

[9] WhyIslam? es una asociación de voluntariado que pertenece al Islamic Circle of North America (ICNA). Se creó en 1999 con fines proselitistas dirigida a los nuevos musulmanes. Funciona bajo la dirección del ICNA y su presencia es de alcance nacional. Atiende a los musulmanes e interesados mediante una línea telefónica que funciona 24 horas todos los días. Atendiendo la diversidad racial y lingüística, WhyIslam? creó la estrategia de incluir entre sus asesores telefónicos a musulmanes que dominan el español o el chino, como tal es una estrategia que permite llegar a un sector particular de interesados y musulmanes principiantes que por sus características culturales y lingüísticas necesitan este recurso para reforzar su integración y práctica en el islam. Cuenta además con un portal web en inglés y español donde se puede interactuar mediante un chat, cuentan demás con página Facebook y un canal de videos en YouTube. Si bien WhyIslam? no es una OLM es necesario rescatar la función que tiene este espacio entre la comunidad latina musulmana. La manera en cómo se expone aquí es a partir de un caso de conversión, el de Nahela Morales. A partir de este caso puede mostrarse no sólo la manera en cómo las OLM transversalizan organizaciones islámicas, sino que actores individuales son posicionados como vinculo o portadores de la oferta islámica, en este caso para el sector latino a través del español. Permite observar la actividad de estos actores individuales que suman a su función proselitista su participación e influencia con OLM y musulmanes latinos. WhyIslam? en español, según narró Nahela Morales nació como un proyecto de los líderes de ICNA, pero se echó a andar con la entrada de ella. La 
panish, una organización musulmana de hispanohablantes, fundada en 2003 en Houston, Texas, por Mujahid Fletcher, un americano-colombiano, y uno de los quince imames latinos de Estados Unidos ${ }^{10}$ quien no estuvo presente en el evento de abril, IslamInSpanish fue representado por el moderador Yahir «Jalil» Navarro, un inmigrante mexicano (de la ciudad de Monterrey) convertido al islam en 2013, que actualmente es el director de IslamInSpanish Outreach Center of Dallas, mientras que Wesley Lebron ${ }^{11}$ fue el representante de WhyIslam? que organizaba el evento, Nahela Morales, comisionada por el ICNA para crearlo tampoco estuvo presente pues ella ahora trabaja en Embrace, un nuevo proyecto de ayuda a musulmanes conversos.

El fin de semana previo al evento fueron presentados los conferencistas en una página creada ad hoc: Foro islámico global ${ }^{12}$ a través de una breve reseña diseñada por género, podemos notar que esta forma de presentación es una discreta alusión al hecho de que el islam al que se adhieren los participantes no abunda en la teoría de género y que la promoción de las mujeres, así como la demostración de que las mujeres no son inte-

historia de conversión de Nahela Morales es importante para comprender otras formas de Dawah entre latinos que incluye como oferta la proyección de éxito social y espiritual tras la conversión en una población étnica que, según se ha descrito en capítulos anteriores, está por debajo de cualquier otro grupo racial hablando de aspectos sociales y económicos. MEDINA, Arely, op. cit. p. 189.

[10] "In 2003, the IslamInSpanish group was founded in Houston, Texas by Mujahid Fletcher. The group's mission is to produce and disseminate audio and visual media for Latinos to learn about Islam in the Spanish language and history. IslamInSpanish has reportedly produced over500 audiobook titles and 200 video programs including their IslamInSpanish television show, all of which showcased their Latino Muslim heritage and reversion back to Islam. The group also holds large open house events for Latinos who are not Muslims that include a lesson in the history of Islam in Spain. Weekly classes are also held in Houston, Dallas, and New Jersey. "IslamInSpanish inaugurated a 5,000 square foot Latino Islamic center, with a media production studio, museum on the history of Islamic Spain and a Spanish-speaking mosque" en ESPINOSA, Gaston, Harold MORALES, Juan GALVAN, "Latino Muslims in the United States Reversion, Politics, and Islamidad", Journal of Race, Ethnicity, and Religion. Vol. 8, Issue 1 (June 2017), 13-14

[11] Wesley Lebron es un joven converso al islam de origen puertorriqueño nacido en Passaic, Nueva Jersey. Educado en una familia pentecostal, se convirtió al islam en 1998 y más adelante viajó a Arabia Saudita a estudiar, regresó al año siguiente y se matriculó en la Universidad de Mishkah donde obtuvo una licenciatura en estudios islámicos. Ha ocupado diversos puestos importantes dentro de la comunidad musulmana en Estados Unidos, es profesor de estudios islámicos y de árabe para principiantes en la Academia Miftahul Uloom, una escuela islámica de educación para niños ; formó parte del Consejo Asesor Musulmán Americano de Illinois, fue Imam en la mezquita Jam-e-Masjid en Nueva Jersey. Actualmente es Coordinador nacional hispano de Dawah para WhyIslam y coordinador de conversos para la Muslim American Society en NY.

[12] https://www.facebook.com/ForoIslamicoGlobal/ 
lectualmente inferiores, incluso que ellas pueden ser teólogas (como el caso Mariam Saada) no va acompañada de un discurso sobre la construcción social del género; se enfatiza que hay una naturaleza femenina, sugerida por el hecho de que en su semblanza curricular el primer punto al presentar a las mujeres es preponderar su rol como madres (no ocurre esto en el caso de los hablantes masculinos), utilizar el color rosa (color asociado a la feminidad), y, finalmente, se subrayar que todas las mujeres visten el hijab, que aunque para una audiencia no musulmana sea el símbolo del islam, sabemos que su uso refiere a una determinada interpretación del islam.

El velo es icónico aquí, al igual que las decoraciones de los diversos oradores: ya sea una biblioteca, que connota conocimiento, o una imagen "piadosa" (de la kaaba). Algunas actividades musulmanas en línea no son específicamente religiosas o islámicas en su orientación, aunque sus protagonistas pueden exhibir un comportamiento musulmán paradigmático en su participación y promulgación de principios islámicos. El indicador puede ser sutil y determinar los límites entre lo que representa una actividad islámica o un comportamiento musulmán es problemático. Un saludo en línea de "al-Salamu alaykum» puede ser suficiente para presentar un correo electrónico como islámico, incluso si su contenido es estrictamente comercial. Ciertamente hay margen para definir una etiqueta islámica en Internet, adaptando los principios tradicionales a la era de la información. ${ }^{13}$ En este conjunto tan codificado que remite a los estándares del islam en la web, anteriormente podíamos observar un elemento disruptivo, el sombrero mexicano, que hacía referencia al latinoamericanismo del islam, en este ejemplo el sombrero no está menos codificado que el hijab, pero refiere a la discusión interna de las identidades y el hecho religioso.

También se presentaron videos de algunos de los conferencistas para animar al auditorio a asistir a estas dos tardes de charlas, en donde la organización fue realizada de manera estricta, con un tiempo para las intervenciones limitado y controlado, y donde las participaciones fueron introducidas y puntualizadas por el moderador. Durante el evento se anunció, en una banda deslizable abajo, una línea telefónica invitando a ponerse en contacto con las personas de WhyIslam? para saber más sobre el islam, en ingles y en español (es un número telefónico de Estados Unidos).

Esta doble jornada de conferencias en línea es continuación de una primera iniciativa de musulmanes latinos en los Estados Unidos, organizada esa vez solamente por IslamInSpanish, la Primera convención de

[13] CESARI, Jocelyne "La communauté virtuelle de l'islam sur Internet", L'Islam à l'épreuve de l'Occident, dir. Jocelyne Cesari, Paris 2004, 164-180. 
musulmanes latinos en Houston, el 17 de noviembre de 2016, donde participaron algunos de los conferencistas que ahora se presentan, por ejemplo, Mariam Saada y Reymundo Nur. Podemos decir que este nuevo coloquio, ocurrido en abril, representa una concretización de las relaciones entre IslamInSpanish y WhyIslam? (o el ICNA). De este evento han surgido algunas conferencias posteriores, utilizando la misma plataforma para su difusión y se ha dado respaldado al Congreso Internacional Islámico de Hispanohablantes Al-Andalusia ${ }^{14}$, llevado a cabo del 11 al 15 de mayo, organizado por Al-Andalusia Education ${ }^{15}$, un proyecto educativo impulsado por Mohammed Idrissi ${ }^{16}$, la Mezquita Al-Hidaya Sevilla y la asociación Al-Andalusia for Humanity ${ }^{17} \mathrm{en}$ el que participaron los mismos conferenciantes y algunos más, pero con algunas diferencias importantes, por ejemplo, un buen numero de horas fue dedicado al concurso de recitación del Corán, con una sección para niños y una para adultos, donde encontramos participantes originarios de países latinoamericanos, estadounidense, de España, Portugal y Marruecos; y migrantes de países mayoritariamente musulmanes residentes en estos países.

El evento del Foro islámico fue pensado para ser mundial, y en efecto, en la difusión se anunció el evento en los diferentes usos horarios del mundo musulmán, del norte y del sur, después México, Malasia, Marruecos, Arabia Saudita y Argentina. Faltó Sudáfrica, lo que es sorprendente pues los musulmanes de ahí rara vez se ausentan de los eventos concernientes al islam mundializado, además de que los fundadores del ICNA tienen un origen parecido a algunas organizaciones en Sudáfrica, es decir, son originarios del sudeste asiático. ${ }^{18}$ En los comentarios en directo

\section{[14] https://www.facebook.com/CIIHA.AlAndalusia/}

[15] https://alandalusia.org/?v=52032b23cba2

[16] Mohammed Idrissi es hermano de Hassan Idrissi, presidente de la Comunidad Musulmana de Sevilla Al-Hidaya. Ambos son muy activos políticamente, recientemente han organizado varias manifestaciones contestando a comentarios que consideran islamófobos por parte del partido Vox, hacen trabajo comunitario, y coordinan redes de ayuda a migrantes musulmanes. https://www.cope.es/actualidad/espana/noticias/una-mezquita-sevilla-responde-dura-reflexion-abascal-sobre-yihadista-detenido-20190423_400274 , https:// www.20minutos.es/noticia/4211647/0/coronavirus-una-mezquita-de-macarena-y-dos-entidades-musulmanas-ofrecen-sus-espacios-a-junta-y-consistoriol

[17] En Sevilla coexisten dos mezquitas, la ya mencionada Mezquita Al-Hidaya Sevilla y la Mezquita de Sevilla, que corresponden a dos grupos diferentes, los segundos son, por su origen, cercanos al Movimiento Mundial Morabitun. Sin embargo los dos colaboraron en este evento, uno representado por Mohammed Idrissi y el otro por Abdelgani Melara.

[18] MCDONOUGH, Sheila, "Muslims of Canada", in The South Asian Religious Diaspora in Britain, Canada, and the United States, eds Harold Coward, John R. Hinnells y Raymond B. Williams, Albany 2000, p. 173-189; SADOUNI, Samadia, "Ahmed Deedat et l'islam indien en Afrique du Sud”, Archives de sciences sociales des religions, 139, (2007), 101-118. 
se pudieron ver asistentes de Indonesia. El número mayor de personas viendo el evento llegó a 178 (el sábado después del medio día) aunque la grabación del evento, difundida después, llegó a alrededor de 500 visitas $^{19}$. En los comentarios también pudimos advertir la presencia de algún troll, pero en general los oyentes fueron musulmanes que querían aprender un poco más o saludar a uno u otro de los conferenciantes.

Las intervenciones vinieron de diferentes corrientes del mundo hispano, aunque por el acento se puede apreciar que no todos son hispanohablantes de nacimiento. El país más representado fue sin duda Estados Unidos (y sobre todo Puerto Rico, con la asociación de 3 Puerto Rican Imams ${ }^{20}$ ) pues son la conexión entre el mundo anglófono y el mundo hispano. ${ }^{21}$ Las ciudades de Ceuta y Melilla fueron también cruciales, pues se pudo observar gran presencia de asistentes de estos lugares. Es de destacar la maestría del árabe y la perfección del acento. En conjunto dan una idea formidable de la expansión trasnacional de esta organización capaz de movilizar eruditos del islam de diferentes horizontes. Lo mismo ocurre con la corriente principal del islam que se predica, porque si bien es cierto que un gran número de ellos han estudiado en Arabia Saudita y manejan la metodología wahabita de un islam formateado, descrito por Oliver Roy, que es el más difundido en América Latina, es imposible referirse a una sola influencia. Esto es consistente con la imagen del ICNA, que en sus diferentes actividades manifiesta una pluralidad de corrientes, como vemos

[19] Aunque según el ICNA el evento alcanzó las 36, 000 visitas. https://www.icna.org/whyislam-hosts-1st-intertl-virtual-hispanic-muslim-conf/ En Youtube no rebasan las 1000 visualizaciones. En la página del ICNA se publicó lo siguiente sobre el evento: "La conferencia obtuvo más de treinta y seis mil visitas en todas las plataformas y más de quinientos comentarios positivos. Un miembro de la audiencia llamado Miriam, una mexicoamericana que vive en Nueva York, dijo: 'Esta es la primera vez que veo información como esta presentada en español'. Hubo muchos comentarios positivos, y muchos asistentes preguntaron cuándo se organizará la próxima conferencia. Aquí hay algunos otros comentarios de la audiencia: 'Qué hermosa conferencia; me está haciendo reflexionar mucho alhamdulillah. Que Allah los bendiga a todos'; Anabel de Granada, España: 'Masha'Allah, me alegra ver que muchos de los panelistas son conversos, ellos mismos. Me encantaría llegar a este nivel algún día. Me prepararé con ese propósito para compartir el islam con otros, insha'Allah'; Nallely de Ciudad de México, México: 'JazakumAllahukhaiyran por todo este conocimiento y por inspirarnos. Esta es una renovación de nuestra fe alhamdulillah'; Hermana Nawal de Mátaro, España: 'Gracias. Esta ha sido una conferencia bendecida. He aprendido mucho'; dijo Víctor de Santiago, República Dominicana: 'Gracias por permitirnos escuchar a grandes oradores que no solo comparten con nosotros sus conocimientos, sino también su humanidad'»

[20] https://3puertoricanimams.org/imams-news/

[21] MANNING, Marable, Adina POPESCU, Khary JONES, Patricia LESPINASSE, New Black Renaissance: The Souls Anthology of Critical African-American Studies, London 2015, p. 352 . 
en el evento "Indeed, I am near" que tuvo lugar casi al mismo tiempo (11 y 12 de abril). ${ }^{22}$

¿Por qué nos parece importante dedicar un artículo a esta conferencia? Primero por proporcionar material para los muchos estudios ya dedicados al islam y su proyección en la web y para enriquecer el conocimiento de iniciativas que no tienen nada que ver con el reclutamiento yihadista, que más a menudo atraen la atención, pero que revelan el vigor del islam en español en este conjunto que, según Jocelyne Cesari, está dominado por musulmanes occidentales. ${ }^{23}$ La comunidad virtual española ya ha sido explorada por Arturo Guerrero Enterria, en su obra Descodificando el islam: el islam en internet en España ${ }^{24}$, pero su trabajo no consideró el islam hispanoamericano en su conjunto, aunque es particularmente consciente de los avances tecnológicos y los acercamientos que estos posibilitan. Además de que en efecto, pocos estudios se han dedicado a la apropiación por parte de la muslimosfera de las herramientas como zoom y sus equivalentes que garantizan una interactividad superior. Este documento busca ser una reflexión general sobre las religiones mundializadas y el COVID-19, y aportar un elemento de análisis importante, en la medida en que, por un lado, vemos un esfuerzo de dawah continuo, a pesar del encierro, o que incluso se amplía gracias a él y, por otro lado, propone una forma importante de mantener una actividad comunitaria a través de internet; finalmente, da una idea sobre la recomposición más contemporánea de una parte del islam latino, y quizás de ciertos grupos musulmanes globalizados. La noción de religión globalizada se refiere a la idea de que las religiones, que tienen seguidores en todo el mundo, con diferentes culturas y menos experiencia histórica constituyen una versión simplificada de sus dogmas y prácticas ${ }^{25}$ lo que podemos ver claramente en el islam en América donde la rama sunita en su versión más ortodoxa wahabita, es la que domina el entorno islámico. ${ }^{26}$

En esta perspectiva, consideramos que este tipo de conferencias se inscriben como parte de un linaje de este islam globalizado proclama-

[22] https://aboutislam.net/reading-islam/research-studies/icna-symposium-2020-indeed-iam-nearl

[23] CESARI Jocelyne,op cit, 164-180.

[24]GUERRERO ENTERRIA, Arturo, Descodificando el islam: el islam en internet en España, Valencia 2018.

[25] ASAD, Taleb, Genealogies of Religion: Discipline and Reasons of Power in Christianity and Islam, Baltimore 1993.

[26] STRENSKI, Ivan, "The Religion in Globalization", Journal of the American Academy of Religion, vol. 72, no. 3, 2004, 631-652 
do por Olivier Roy ${ }^{27}$. Un islam que se ha enriquecido durante los últimos veinte años en el espacio de la Web, y que utiliza los recursos de nuestro tiempo para sus actividades proselitistas, pero también para la difusión del conocimiento islámico ('alm) a sus seguidores ${ }^{28}$. Esto nos permite encajar nuestra reflexión en el marco teórico realizado por Roy y Césari sobre la adaptación del islam como otra religión al contexto actual. Esta adaptación que ha sido vista por el historiador como una interactividad continua entre musulmanes y no musulmanes, la podemos ver claramente en este caso. Y aquí el internet funciona como un medio para comprender, interpretar y transmitir formas de conocimiento religioso a una variedad de audiencias. Como menciona Gary Bunt estos procesos no son estáticos, sino que evolucionan y se han convertido en un complemento natural de las formas tradicionales del discurso islámico ${ }^{29}$.

\section{Los retos del islam entre la comunidad hispanohablante}

Podemos advertir que, aunque este evento es organizado por WhyIslam? (el ICNA) e IslamInSpanish, quienes han promovido la idea de un islam latino, en esta ocasión se prefirió utilizar en el título el término "hispanos", muy probablemente para poder incluir a España, Ceuta y Melilla, pero también porque da lugar a la inclusión del imaginario sobre Al-Ándalus, no solo como tierra de convivencia, muy presente en el discurso de diferentes grupos islámicos, sino como el momento histórico en donde "Europa" o el "mundo occidental", fue musulmán. ${ }^{30}$ Así se constituye un todo más allá de las fronteras nacionales. Aquí la facultad específica de Internet es que nos permite reproducir y mantener formas de identidad comunitaria a gran distancia, mientras que la distinción entre 'aquí' y 'allí' todavía puede perdurar, 'allí' ya no está muy lejos, "aquí" tenemos la formación de un mundo bien definido dentro del espacio blando de la web. Podemos hablar de la performatividad de este compromiso hispano, este conjunto creado por la posibilidad del reencuentro a través de pantallas y dando lugar a una identidad más allá de las diferencias fundamentales de la experiencia.

[27] ROY, Olivier, L'Islam mondialisé, Paris 2002.

[28] FAKHRUROJI, Moch, "Muslims Learning Islam on the Internet", In: Woodward M., Lukens-Bull R. (eds) Handbook of Contemporary Islam and Muslim Lives, Berlin 2019, 1-17

[29] BUNT, Gary R., Hashtag Islam: How Cyber Islamic Environments are Transforming Religiou sAuthority, Chapel Hill 2018, p. 4.

[30] GONZÁLEZ ALCANTUD, José Antonio: El mito de Al Ándalus. Córdoba 2014. 
Es por ello que la latinidad que el ICNA o IslamInSpanish promovían hasta hace algunos años, en este evento se ve desdibujada, pues se busca imponer lo hispano para incluir al mundo ibérico en esta nueva ummah cibernética que quiere formarse. Contrario a la americanización, los angloparlantes (patente en su acento) encuentran o refuerzan su hispanidad y la identifican con el islam (varios de ellos son nacidos en Estados Unidos, pero de familias mexicanas, puertorriqueñas, etc.). La referencia a un Estado nacional se olvida aquí, y observamos, por ejemplo, que Mariam Saada se asume como "egipcia» (que no lo es) o Hazel Gómez, como mexicana (tampoco lo es). Un reclamo menos desde los orígenes que desde otro espacio, el construido por la conferencia. No es solo un espacio virtual, también es un espacio imaginario ${ }^{31}$, que busca la unidad, bajo el nombre del islam, de un territorio que va de Marruecos a California, pasando por Sudamérica, para generar la idea de un todo "sur - sur»; en este caso, Estados Unidos ya no es «el norte», sino que pertenece a otra configuración que también se refiere a la retórica decolonial: la presencia del islam en los Estados Unidos produce un cambio, si no geográfico, al menos geopolítico. Los orígenes se movilizan para una proyección hacia el futuro. ${ }^{32}$ También podemos advertir el deseo de reivindicar el islam hispano a través de importantes autoridades religiosas y, en este contexto, el dominio del árabe no equivale al reconocimiento de una subordinación a este o aquel Estado en el Medio Oriente, sino a la legitimidad de los eruditos islámicos hispanoamericanos.

Podría parecer que en este evento se observa la unidad del islam hispanoamericano, en contraparte a los desencuentros en el resto del mundo musulmán, pareciera que los musulmanes han logrado un espacio de acuerdo. El animador, que interviene entre cada conferencia, recuerda las circunstancias amigables en las que conoció a uno u otro de los conferenciantes, todos son amigos, los recuerdos se entrecruzan, la dawah parece ser la misma en España que en México y Estados Unidos. Vemos la diversidad de caminos y compromisos islámicos, en la forma de la barba y en el discurso, y, sin embargo, aunque parece que todos son admitidos en

[31] ROY, Olivier, "Le néo-fondamentalisme islamique ou l'imaginaire de l'»oummah» », Esprit, avril 1996, 80-107 (DOI: 10.2307/24276722). Véase también SCHMIDT, Garbi, "The transnational Umma - myth or reality? Examples from the western diasporas", Muslim World, 95(4), 2005, 575-586.

[32] Ver por ejemplo la publicación en Facebook de la página Hablamos Islam, publicada el 13 de abril de 2017, que dice: Este año, en el ICNA-MAS Convention en la ciudad de Baltimore, Maryland, escuchen \#lavozlatina. Nuestras perspectivas, nuestras experiencias, nuestras voces. El 14 hasta el 16 de abril. Aprendan sobre nuestros derechos como musulmanes y/o latinos viviendo en los Estados Unidos, la época de la lucha por los derechos civiles y cómo se compara con el presente, el liderazgo en la comunidad musulmana, inculcando un sentido de identidad en nuestros hijos, y mucho más, insha'Allah. 
este espacio virtual que se construye, es sólo una apariencia pues en este evento no está representada la diversidad del islam latino e hispano, todos los participantes están ligados de alguna forma al ICNA. Figuras que otrora parecían claves no figuraron en esta ocasión, por ejemplo, Isa Rojas de México, quien desde hace un tiempo trabaja para la WAMY, sin hablar de todas las corrientes del islam que son muy activas en Latinoamérica, como la Naqshbandia, la orden sufí Halveti -Yerrahi, el movimiento "nur" de Said Nursi, los chías, entre muchos otros; la ausencia de estos actores hace que no podamos hablar de que hay un islam uniforme.

Podríamos decir que son igual de importantes los participantes como los ausentes, pues nos plantea la cuestión clave sobre el liderazgo de los musulmanes en Hispanoamérica, podemos encontrar organizaciones como la Angeles Latino Muslims Association (LALMA) cuya historia está representada por Reymundo Nur y Mariam. Saada, que demuestran la conexión transnacional. Pero también uno puede preguntarse por la presencia de Isa García, una de las mayores autoridades latinas, un argentino radicado en Colombia, graduado de La Meca, traductor del Corán y que asiste a todo tipo de reuniones y eventos comunitarios y universitarios, ¿qué o quien confiere a estos personajes tan diversos autoridad?

Como vemos la discusión sobre las especificidades que debería tener un islam dirigido a latinos ya no está más en el debate, la inclusión de España rompe con este discurso. Por ejemplo, la mexicanidad que se veía reforzada por símbolos como el sombrero charro, ya no está en discusión, no observamos preguntas sobre la ropa, la comida, o la hibridación. Aunque esto no corresponde con todas las comunidades de musulmanes en Latinoamérica, sino que responde a la agenda del islam en Estados Unidos que tiene cada vez más presencia en América Latina y España, a través de diversas organizaciones de dawah y asistencia como Helping Hand for Relief and Development, quienes han colaborado otorgando ayuda económica o en especie ante desastres naturales como los terremotos en México o huracanes en Puerto Rico, o que hacen donaciones de carne a comunidades musulmanas latinas en festividades como el Eid al-adha. En las ponencias no encontramos una propuesta sobre especificidades del islam para musulmanes latinos, o una forma de islam hispano, sino que se habla de una hispanidad musulmana, que practica el mismo islam, un islam que debe regresar al hogar, salir de las mezquitas y convertir cada casa en una.

$\mathrm{Al}$ igual que numerosos grupos cristianos en el contexto del COVID-19 han propuesto un regreso al esquema de las comunidades primitivas, la propuesta de algunos conferencistas como Mariam Saada, es convertir cada hogar en una mezquita y sugiere dedicar un espacio dentro del domicilio dedicado a actividades religiosas. Hay dos aspectos a destacar en 
esta propuesta, por un lado, al hablar del islam latino o hispano, donde la mayoría de los conversos pertenecen a familias de mayoría cristiana, este planteamiento puede o busca convertirse en una forma de dawah desde el ámbito micro como hacían los hermanos musulmanes en sus inicios. Por otro lado, para las familias totalmente musulmanas, el espacio doméstico se convierte también en un espacio religioso ${ }^{33}$, siguiendo con esta idea del islam político de que el islam es una forma de vida que debe regir todos los aspectos de la vida de los individuos y las familias, determina la educación de los niños, la postura política y hasta se propone una economía islámica.

En todo ello radica la importancia de establecer una autoridad religiosa y política, que en los Estados Unidos (a diferencia de Francia), es un medio de acceder a la vida pública, para entender esto podríamos poner como ejemplo el caso de Nahela Morales, de quien hablamos anteriormente, la fundadora de WhyIslam?, quien gracias a su labor proselitista fue invitada en 2016 por el presidente Barak Obama a celebrar el iftar junto con otros líderes religiosos. ${ }^{34}$

Es decir que son tres los grandes retos que presenta el islam "latino" frente a la pandemia del coronavirus: ¿cómo construir una comunidad (ummah) a pesar de la distancia y de las múltiples corrientes que abundan en la red y en el territorio? ¿Cómo establecer una autoridad religiosa dentro de una religión no institucionalizada? ¿A qué mecanismos puede recurrir el islam político en sociedades laicas y de mayoría cristiana?

\section{Ser musulmán en tiempos de COVID-19}

La conferencia, preparatoria para el Ramadán 2020, se centró en reflexionar sobre el ser musulmán en tiempos del COVID-19. "hubo un total de quince oradores que representaban a nueve países, considerados líderes en la comunidad global hispana musulmana y expertos en sus campos, presentando una variedad de temas, como la elevación espiritual, la historia islámica, la psicología de los nuevos musulmanes, la estabili-

[33] Mariam Saada mencionó en su página personal de Facebook a un grupo transnacional, ThinkingMuslimWomen, quienes habían publicado el 6 de abril imágenes para la organización de un lugar de oración doméstica, con este mensaje "iAquí hay 6 formas de hacer que su \#StayAtHome sea más beneficioso y también aumente su ibaadah!"

https://www.facebook.com/thinkingmuslimwomen/photos/pcb.1611128922368256/16111283 35701648/?type $=3 \&$ theater

[34] https://nahelamorales.com/about/ 
dad emocional y la resiliencia a la luz de los acontecimientos actuales, el mantenimiento de una vida equilibrada, la productividad, el servicio a la humanidad, la paternidad y la preparación para el Ramadán”. ${ }^{35}$ Cabe señalar que el tema de la pandemia no se trata como tal, a diferencia de lo que sucede en otros contextos religiosos donde se interpreta, a veces en términos milenarios o por la ira de Dios. Tampoco hay discursos conspiradores, como se ha observado en otros contextos, incluidos los musulmanes. ${ }^{36}$.

El COVID-19 ha dado la oportunidad de mostrar la riqueza de recursos que ofrece el islam en una situación donde la experiencia comunitaria es imposible. Citamos en especial la conferencia de Aziza Di Bello, una psicóloga uruguaya, que propuso métodos de respiración para soportar el estrés del confinamiento. Las practicas descritas y recomendadas aquí son las de cualquier clase de relajación, y solo son islámicas en la medida que son practicadas por una mujer musulmana utilizando el hijab. Por lo tanto, es una islamización de lo psicológico o la aceptación, por parte de los musulmanes, de técnicas profanas, lo que muestra la forma en que los círculos militantes se posicionan en todos los sectores de la vida pública. Además, el moderador a menudo ha enfatizado la importancia de sobresalir como musulmanes en todas las profesiones. En cualquier caso, en cuanto a la psicología y las terapias conductuales, a menudo son trabajos dejados a mujeres, y en los últimos años las especialidades de la psicología islámica se han multiplicado, en este evento tuvimos también la participación de Yessica Martínez, psicóloga de profesión. Estas especialidades revelan a su vez a la generación más joven de mujeres musulmanas latinas, y podemos aquí ver un relevo generacional y una participación de estas mujeres desde su práctica profesional, en ocasiones, anterior a su conversión, que orientan a una práctica islámica.

Después de varias décadas en que el islam ha crecido en Latinoamérica y el mundo ibérico, encontramos varias generaciones, las mujeres que tienen más años dentro del islam, pensando que la mayoría de las mujeres musulmanas en Iberoamérica son conversas, han tomado la iniciativa de crear grupos o sitios en internet que orientan a las nuevas musulmanas en temas que para esta comunidad se tornan relevantes como el matrimonio, el noviazgo, la relación con la familia, el lugar de la mujer en la sociedad islámica, hasta temas tan polémicos como la poligamia. Así como fungir como guías de las nuevas musulmanas en su práctica islámica, enseñándoles cosas como la oración, la forma de vestirse (uso del hijab o el niqab),

[35] https://www.icna.org/whyislam-hosts-1st-intertl-virtual-hispanic-muslim-conf/

[36] https://www.saphirnews.com/La-muslimosphere-face-au-Covid-19-Une-punitiondivine-au-secours-des-Ouighours-1-3_a27184.html?fbclid=IwAR0X-Tna4vIh2B_A5UxhuuKqhKzGuInlbC06UqZoZqJhp23oVMAfQik66Uo 
cómo hacer el wudu (ablución). Mientras que las mujeres más jóvenes han asumido un papel más dinámico desde su perfil profesional, es decir, desde especialidades terapéuticas, legales, en ciencias sociales, etc.

Las otras intervenciones versaron sobre temas más islámicos, por ejemplo, la intervención de Zaid Abdelrahim "La felicidad en el islam" o la de Isa García sobre el Corán y sus lecturas. El elemento más importante es una especie de paradoja de territorialización y desterritorialización. De hecho, si insistimos en el compromiso de los hombres y mujeres musulmanes en sus lugares de trabajo, su religiosidad parece extraterritorial: es decir, se vive en el espacio doméstico, con la insistencia en el hecho de que la mezquita no es una necesidad y que finalmente la época del COVID-19 hace que más musulmanes que viven en contextos no islámicos vivan lo que otros ya están experimentando: vivir lejos de una mezquita en tiempos de normalidad. En este sentido, las conferencias de Facebook o a través de zoom son un intento de conectarse con personas dispersas y autenticar su existencia islámica. Por lo tanto, crear una comunidad desterritorializada pero cuya unidad es muy fuerte: primero hacia el islam en español, luego al islam simplemente, sin referencia nacional: internet está creando una comunidad panislámica.

Ciertamente, ya hay grupos de WhatsApp, pero quizás la idea es que los musulmanes dejen de frecuentar mezquitas que no son de su simpatía, lo que a menudo ocurre en contextos «occidentales». La mezquita no es tan importante, ni el número, lo que importa es la calidad del musulmán, que debe ser un musulmán total. En este sentido, las competencias de recitación del Corán, así como el reciente trato sobre la familia, tienen aspectos políticos obvios: se trata de construir una buena comunidad que se establezca desde la infancia, a través de una dawah que comienza con el espacio doméstico y que implica un fuerte control social. Esto continúa con las enseñanzas islámicas, y al observar la biografía de los diferentes hablantes, podemos resaltar la importancia de los lugares de entrenamiento islámico.

¿Cómo se construye una autoridad religiosa dentro del islam hispanoamericano en contextos seculares y laicos a través de la web?

Como demuestra el trabajo de Blunt, ${ }^{37}$ ha surgido una economía innovadora del conocimiento y el proselitismo, que ha provocado un desafío a los modelos tradicionales de autoridad «de arriba hacia abajo». Una economía del conocimiento colaborativa y horizontal, que se conecta en redes entre pares, ha envuelto áreas del ciberespacio islámico. De hecho, vemos

[37] BUNT, Gary R., iMuslim, cit. 
que este encuentro se desarrollo en un equilibrio entre encuentro religioso, de temática estrictamente islámica, y encuentro de interés general, calificado de islámico por la presencia de marcadores musulmanes (vestimenta popular, etc.). Aquí estamos en un campo secular que ha sido devorado por el hecho islámico (como el espacio halal) y se confiere un tinte religioso mediante el adjetivo islámico, por ejemplo el uso del hijab de las personas que intervienen en un campo secularizado como la psicología. Es la interpenetración de los dos mundos, secular y religioso, lo que caracteriza a este islam de la red, donde vemos a los religiosos entrar en el campo político, psicológico, etc. y al revés. Esto ocurre especialmente en tiempos de crisis, como COVID-19, ya que las autoridades religiosas utilizan internet como un medio para regular a los individuos y grupos musulmanes y para la difusión uniforme del conocimiento islámico global. ${ }^{38}$

Efectivamente, la conexión también puede ser inalámbrica, lo que permite una mayor movilidad y una selección de interfaces. En línea, se desarrollan nuevas agrupaciones virtuales y afinidades más allá de los límites tradicionales, basándose en múltiples identidades. Estos desafían y mutan las concepciones previamente convencionales de la identidad musulmana, transponiendo elementos familiares dentro de una interfaz digital $^{39}$, sin embargo, la autoridad, incluso si se desplaza de los países musulmanes a los estudiosos del islam en el mundo hispano, se refiere únicamente a la palabra islam sin entrar en discusiones teológicas. En efecto, una de las características de estos eventos en internet, es que, a pesar de que lo que se promueve es el islam, nunca se nos dice qué es el islam, y aunque como hemos corroborado los participantes pertenecen a diferentes corrientes, no es un tema del que se hable. El islam tiene aquí un significante difuso, libre de tradiciones, escuelas jurídicas y teología.

La comunicación virtual del islam es supervisada por un magisterio islámico, a veces autoproclamado, otras aportado por autoridades religiosas de países predominantemente musulmanes, con títulos en ciencias islámicas y que en ocasiones pertenecen informalmente a una organización internacional (como la organización IslamInSpanish). Es a través de estos eventos que se da legitimidad a las figuras que en ellos participan, se armonizan las opiniones para reafirmar una suerte de autoridad entre los disertantes. Sin duda, como comenta la autora del Qur'an of the oppresse$\mathrm{d},{ }^{40}$ el islam contemporáneo, y en particular el de la web, muestra una

[38] TURNER, Brian S., "Religious authority and the new media", Theory, Culture \& Society, 24(2), 2007, 117-134 (doi.org/10.1177/0263276407075001).

[39] BUNT, iMuslims, p.8.

[40] RAHEMTULLA, Shadaab, Qur'an of the Oppressed: Liberation Theology and Gender Justice in Islam, Oxford 2017. 
democratización del conocimiento: todo el mundo escribe, publica, tiene acceso a fuentes, etc. y esto desde la época reciente en la que la imprenta se refiere al conocimiento islámico (siglo XX).

Estos a menudo se basan en lecturas alternativas de materiales de origen islámico fuera de las influencias "ortodoxas» y controladas por el Estado. Sin embargo, no sabemos quién está detrás de IslamInSpanish o del ICNA, quién lo financia, qué grupo, qué ideología, y los discursos sólo enturbian las aguas. En Internet, varios sitios han sido influenciados directa o indirectamente por aspectos de autoridad e interpretación que surgen de definiciones amplias de contextos interpretativos wahabíes, salafistas, qutubi y sinónimos políticos-religiosos. Los sitios no necesariamente vienen con indicadores claros como quién los financia, apoya o escribe su contenido. Sin embargo, las diferentes asociaciones o grupos están atrapados entre 1) su crítica a los ulemas y el conocimiento sedimentado y 2) el riesgo de un auto-islam (cada uno juega con su propio islam); estas operaciones en la web reconfiguran y legitiman una autoridad religiosa entre estos dos escollos. Esto resuelve el problema de Castells para quien "nuestras sociedades se estructuran cada vez más en torno a una oposición bipolar entre la Red y el yo". ${ }^{41}$ Aquí se convierten en autoridad, la palabra no se da a todos los «yo», sino solo a los guías que se dejan conducir en todos los ámbitos, no solamente religiosos. La pandemia permite una nueva extensión del campo religioso, sin olvidar las grandes epidemias de épocas pasadas, que se creían superadas, y por tanto reactivar conocimientos enterrados.

Podemos ver en las reseñas de los participantes que tienen estudios en diferentes lugares, ponemos como ejemplo los casos de Isa García y Ahmed Bermejo, mientras que uno ha confesado que estudió en La Meca, Bermejo cuenta que él estudió en un pueblo en Marruecos, dentro de una tariqa que tiene relación con el islam mundializado, ya que es sede de la rama Darqawiyia ligada al Movimiento Mundial Morabitun. ${ }^{42}$ Sin embar-

[41] CASTELLS, Manuel. La era de la información. Economía, sociedad y cultura. Vol. 1 México 1996..

[42] Bermejo cuenta su historia en su página de internet http://ahmedbermejo.com/sobre-mi/ El Movimiento Mundial Morabitun tiene una presencia bastante importante en la esfera del islam hispano, no solamente en España sino también en América Latina, por ejemplo en el estado mexicano de Chiapas. Para consultar más sobre el MMM véase DE DIEGO GONZÁLEZ, Antonio «"Se cerraron los psiquiátricos y abrieron los centros islámicos". Contracultura, hippies, psicodelia y neo-sufismo marroquí en la España Contemporánea», Madrid: Abada, 2020; SEDGWICK, M, Western Sufism. From Abbasid to the New Age, USA: OUP, 2016; AL-ITALY, O. Ian Dallas: The shaykh who has no clothes (1994); GONZÁLEZ J. Y GÓMEZ, A. "El Movimiento Mundial Murabitún en España”, Athena Intelligence Occasional Paper, $n^{\circ}$ 20, 25/10/2007. 
go, no se nos habla claramente sobre qué tipo de estudios llevaron a cabo, ¿cuánto tiempo? ¿Qué tipo de programa y hacia quien va dirigido? ¿Estos estudios les confieren el reconocimiento de los eruditos de países mayoritariamente musulmanes? Responder a estas interrogantes nos llevaría a ver la necesidad de realizar un estudio exhaustivo de los programas de formación dirigidos a latinos que se desarrollan en centros educativos en La Meca, en la Universidad Al-Azhar en Egipto (que tiene una gran presencia en AL), en Qom y en Marruecos, principalmente, y compararlos con los que llevan a cabo los originarios de estos países en diferentes universidades, pues como podemos apreciar, en muchos caso estos son estudios básicos de árabe e introducción a las ciencias islámicas, en ningún modo comparables a los cursos completos que se ofertan a los estudiantes regulares, que, sin embargo, al regreso a sus países de origen, les confieren autoridad, ponemos como ejemplo el caso del programa en ciencias islámicas que ofrece la Universidad de Al-Azhar dirigido a latinos, que tiene una duración de tres meses en que se imparten nociones básicas sobre el islam, en español, los estudiantes que realizan esta formación al regresar a sus países tienen automáticamente cierto grado de reconocimiento que puede constatarse en los congresos de exalumnos de Al-Azhar que se realizan en diversos espacios, donde se dan cita algunas de las personas que suelen figurar en los eventos sobre el islam dentro de esta esfera del islam mundializado. ${ }^{43}$ Es también el caso del sufismo, donde algunos conversos pasan unos meses en tariqas en Turquía, Siria o Marruecos, y al volver, esta experiencia les otorga autoridad sobre otros conversos.

Marruecos, Arabia Saudita, Egipto son los tres polos islámicos de este islam hispano sunita. Y aclaramos que sunita porque el centro del islam hispano chiita es sin duda Qom, que tiene un programa especialmente diseñado para latinos, y que otorga una gran cantidad de becas cada año. ${ }^{44}$ La otra forma en que se puede acceder a estudios islámicos es en institutos occidentales, que tienen una gran oferta en línea. Sólo en Estados Unidos existen alrededor de seis universidades, al igual que numerosos centros islámicos que imparten diferentes niveles de educación, aunque estos no otorgan el reconocimiento de los grandes centros de conocimiento de los países mayoritariamente musulmanes.

Entonces, ¿cómo es que se adquiere autoridad religiosa dentro del islam hispano? ¿Las personalidades que hemos visto tienen una autoridad que se gesta en el grupo que ellos han formado o del que forman parte o están respaldados por eruditos que no figuran públicamente? Es aquí donde

[43] http://portal.azharegypt.net/page2.php?page=3\&page1=4\&page2=64

[44] https://www.onlinestudies.mx/universidades/Iran/Al-Mustafa-Open-University/ 
debemos reconocer que la conferencia también tuvo otro propósito, establecer la autoridad de los participantes sobre otros imanes que abundan en la web. Para el caso del islam chiita la cuestión de la autoridad parece más clara, pues hay autoridades de Qom dedicadas exclusivamente al mundo hispano, pero este no es el caso para los círculos sunitas.

Los diferentes imanes que hemos entrevistado a lo largo de los años hablan sobre todo de una autoridad entre ellos (todos se conocen, por haber realizado sus estudios en los mismos lugares) y de una independencia teológica con respecto a Arabia Saudita, por ejemplo. ${ }^{45}$ Por otro lado, el islam propuesto es de hecho una metodología del islam wahabi, simplificada para ser dirigida a poblaciones con poca demanda de ciencias islámicas, que buscan ortopraxía y esencialmente una religión sin teología, comparable a grupos de denominaciones evangélicas y misioneras.

Muchos conversos, al hablar de su experiencia, refieren la simplicidad de la religión islámica (a diferencia de la religión católica de la que provienen) y el valor de una relación directa con Dios. El islam aquí se convierte en el nombre de una religión muy simple: el nombre de la fe en Dios, con una referencia directa a los hispanos, una referencia contracultural, que no aboga por una ruptura con la sociedad en su conjunto, pero sí por la formación de una comunidad.

Sin embargo, está claro que esta comunidad no nació espontáneamente. Debe recordarse que es el poderoso ICNA el que está organizando el evento, y no una autoridad de un país predominantemente musulmán. Por lo tanto, promover la hispanidad islámica es una de las actividades de la organización y no un fin en sí mismo, por lo que sería necesario estudiar al ICNA y sus lealtades para comprender mejor la articulación de este islam hispano, que se extiende más allá de las fronteras de los Estados Unidos.

¿Pretende esta conferencia constituir una autoridad religiosa hispana autónoma, referida vagamente al islam de países predominantemente musulmanes, o agrupar a los musulmanes en una sola comunidad, teniendo cuidado de no trabajar sobre ideologías, para no entran en discusiones sobre puntos de teología que tal vez resulten en fricción con la sociedad en su conjunto? Es necesario hacer un trabajo más amplio que explique este islam flotante.

[45] Habría que hacer un estudio más amplio para el caso de los estudiantes de la Universidad de Al-Azhar, que ofrece un programa en español para estudiantes latinos, quienes en los últimos años se han agrupado para organizar encuentros de exalumnos, eventos, o formar agrupaciones, y que al parecer reconocen la autoridad de Al-Azhar como su centro teológico. 


\section{Conclusiones}

Aunque hablemos de un islam flotante, es decir, un islam formateado y digerido para ser trasmitido fácilmente a través de las redes sociales, las autoridades religiosas están en proceso de constitución y legitimación. En este sentido podemos entender que en los últimos años se hayan creado un gran número de institutos islámicos de formación en países occidentales como en Estados Unidos, Canadá y España. A la par también se han creado numerosas escuelas musulmanas calificadas o no de madrasas. ${ }^{46}$ Esto se percibe más claramente en los lugares donde hay más musulmanes y el islam está más organizado, por ejemplo, en Estados Unidos y Canadá. A esto se suma una legislación que permite el desarrollo de estos centros como la estadounidense o canadiense, mientras que, en algunos países latinos con una legislación más estricta en materia religiosa, y con una comunidad musulmana poco organizada y muy diversificada, como es el caso de México, este sea un tema que no ha podido materializarse. En Estados Unidos existen al menos seis universidades islámicas, aparte de centros de educación básica y centros islámicos de educación no formal, un panorama parecido sucede en Canadá, donde hay por lo menos tres universidades islámicas. Todos estos establecimientos persiguen diferentes objetivos: impartir una educación musulmana de calidad a musulmanes que viven en sociedades no musulmanas y donde no hay una oferta dirigida a este sector, pero principalmente, el objetivo de estas instituciones es construir autoridades o en su caso legitimar las existentes, convirtiendo a estos centros no solo en nichos económicos sino también en espacio de notoriedad para los actores, por ejemplo, el caso de Wesley Lebron quien estudió en la Mishkah University, en Nueva Jersey donde ahora trabaja coordinando los cursos presenciales. ${ }^{47}$

El objetivo principal del ICNA, a nuestro parecer, es crear una comunidad musulmana (inspirada en la comunidad judía) como una cultura dentro de la cultura que le permita posicionarse en términos políticos utilizando esta idea de que, al igual que el mundo islámico-hispano fue víctima de la reconquista, de igual manera hoy los latinos son de segunda categoría en los Estados Unidos. ${ }^{48}$ Proponiendo al islam como una alter-

[46] Con apoyo del ICNA se han desarrollado algunos proyectos educativos como el de Hernán Guadalupe y Wendy Díaz " Hablamos islam niños " que desarrolla material educativo islámico dirigido a los infantes. https://hablamosislamninos.com/about/

[47] http://dawahmonthly.com/2014/08/who-is-wesley-lebron/

[48] Debido a que la Oficina del Censo no proporciona estadísticas sobre religión, las cifras son escasas; no obstante, un estudio realizado en 2007 por el Centro de Investigación Pew estimó que el 10 por ciento de los musulmanes nacidos en Estados Unidos es de origen hispano. Actualmente se estima, en cifras no oficiales, que hay entre 40.000 y 200.000 musulmanes 
nativa al white anglo-saxonprotestant- y como una solución para los países anexos (Puerto Rico).

Para el ICNA la crisis provocada por el COVID-19 es una ocasión formidable para reforzar su actividad, reafirmar sus intenciones y constituir una comunidad virtual donde el tema de la educación, en especial la de los niños, ocupa un lugar preponderante.

latinos en todo el país. https://www.efe.com/efe/america/ame-hispanos/la-poblacion-musulmana-latina-en-ee-uu-crece-y-se-organiza/20000034-3297199 